\title{
Empirical Method for Evaluating Resilient Modulus of Saturated Silty Clay under Cyclic Loading
}

\author{
Zhen Zhang, ${ }^{1}$ Yong Chen, ${ }^{1}$ Guanbao Ye ${ }^{D},{ }^{1}$ Peilin Xiang, ${ }^{2}$ Yan Xiao, ${ }^{1}$ and Qiong Wang ${ }^{1}$ \\ ${ }^{1}$ Key Laboratory of Geotechnical and Underground Engineering of Ministry of Education, \\ Department. of Geotechnical Engineering, Tongji University, Shanghai 200092, China \\ ${ }^{2}$ Department. Chief Engineer, Research Institute of Shanghai Urban Construction, Shanghai 200125, China
}

Correspondence should be addressed to Guanbao Ye; guanbaoye@gmail.com

Received 11 May 2020; Revised 5 September 2020; Accepted 5 October 2020; Published 21 October 2020

Academic Editor: Chunshun Zhang

Copyright ( $\odot 2020$ Zhen Zhang et al. This is an open access article distributed under the Creative Commons Attribution License, which permits unrestricted use, distribution, and reproduction in any medium, provided the original work is properly cited.

Resilient modulus of soil is crucial for the design of a structure on a foundation subjected to a cyclic loading (e.g., traffic load or machine vibration load). This paper conducted a series of dynamic triaxial tests of saturated silty clay, considering the influence of the factors of cyclic stress ratio (CSR), static deviatoric stress ratio (SDR), and overconsolidation ratio (OCR) on the resilient modulus and dynamic damping ratio of the soil. A cyclic loading with a form of half sine wave was used to model the traffic loading. The results showed that the soil was prone to failure under a higher SDR, even though the applied CSR was less than the critical CSR. The saturated silty clay performed a strain softening behavior and its dynamic properties deteriorated significantly when higher CSR and SDR and lower OCR were involved. Based on the test results, an empirical method with a form of exponential function was proposed to evaluate the resilient modulus of the soil, considering the combined effects of CSR and SDR and OCR. The proposed method was verified through a comparison with the test results in this study and from literatures, and some recommendations for its application were offered.

\section{Introduction}

Subgrade consisting of saturated soft soil would be softened after it goes through million times of traffic loading in service $[1,2]$. Such mechanical feature would result in an additional roadway settlement and shortening the road serviceability life [3-5]. For example, Saga airport road built on Ariake clay in Japan suffered an astonishing settlement after it went into operation [6].

Thus, properly evaluating the dynamic properties of soil as well as its deterioration characteristics is crucial for the design of a structure on a foundation subjected to a cyclic loading (e.g., traffic load or machine vibration load). Previous studies indicated that the dynamic behavior of soil is influenced by many factors, including the amplitude and form of cyclic loading, initial static deviator stress, and overconsolidation ratio [7-10]. Zhao et al. [11] indicated that increasing the cyclic stress level and the initial deviatoric stress would accelerate the attenuation of the resilient modulus of soft soil. Thian and Lee [12] performed a series of cyclic constant-volume direct simple shear loading tests on Malaysia offshore clay and found that the overconsolidated specimen reached the cyclic shear strain at failure faster than the normally consolidated specimen. In addition to the laboratory researches, some empirical methods for predicting the resilient modulus of soil have been established [13-16]. However, they are still rarely used in practice due to the complexity of the combined effects of a few influence factors. Therefore, it is necessary to develop a simple method to evaluate the dynamic properties of soil involving the influence factors for practice.

In this paper, a series of dynamic triaxial tests were conducted to investigate the dynamic behavior of saturated silty clay. The influences of the factors cyclic stress ratio (CSR), static deviatoric stress ratio (SDR), and overconsolidation ratio (OCR) on the resilient modulus and dynamic damping ratio were considered in the study. Finally, an empirical model was proposed to calculate the 
deterioration characteristics in resilient modulus, involving the influence factors of CSR, SDR, and OCR. The feasibility of the proposed model was verified through a comparison with some reported test result, and some recommendations for its application were offered.

\section{Test Preparation and Scheme}

The saturated silty clay sampled at a depth from $8 \mathrm{~m}$ to $12 \mathrm{~m}$ in an area of the high-tech district in Suzhou, China, was prepared for this study. A half sine wave function considering cyclic stress ratio (CSR) and static deviatoric stress ratio (SDR) was used to better model the traffic loading.

2.1. Soil Sample Preparation. The in situ soil samples were obtained by a thin-walled sampling tube with an internal diameter of $101.6 \mathrm{~mm}$ and height of $508 \mathrm{~mm}$. In the dynamic triaxial test, the soil was remolded and prepared, referred to ASTM D4220/D4220M [17]. Table 1 shows the main properties of the remolded soil.

The natural soil was dried and grinded, and then the soil powder was obtained through $2 \mathrm{~mm}$ sieve. According to the dry density and the water content of the natural soil, the corresponding water was added and thoroughly mixed with the dry soil powder. The mixture was filled into a saturator layer by layer. The soil specimen was saturated in a vacuum chamber for $1 \mathrm{hr}$ by pumping vacuum and then sealed for $12 \mathrm{hr}$ after saturation. The dynamic triaxial tests were performed using the GDS dynamic triaxial testing system. The cylindrical soil specimen had a diameter of $39.1 \mathrm{~mm}$ and a height of $76 \mathrm{~mm}$. The specimen was enclosed by a thin rubber membrane and placed between two rigid plates inside the pressure chamber. The saturation process was executed until Skempton's B-value greater than 0.97 was achieved.

2.2. Test Schemes. Karlstrom and Bostrom [18] experimentally found that the traffic loading had features of low amplitude, low frequency, and long wavelength. As compared with sine wave model [19], Lu and Jeng [20] indicated that the dynamic stress transmitted to the subgrade was mainly a low-frequency one-way pulse wave rather than a two-way sine wave. Therefore, a half sine wave function was used to model the traffic loading in this study, which is characterized by three factors: loading frequency, cyclic stress ratio (CSR), and static deviatoric stress ratio (SDR). The applied cyclic loading is expressed in the following form:

$$
\begin{aligned}
F(t) & =2 \sigma_{3}^{\prime}(\operatorname{SDR}+\operatorname{CSR}|\sin (\omega t)|), \\
\mathrm{CSR} & =\frac{\sigma_{d}}{2 \sigma_{3}^{\prime}}, \\
\mathrm{SDR} & =\frac{\sigma_{s}}{2 \sigma_{3}^{\prime}} .
\end{aligned}
$$

where $\sigma_{3}^{\prime}$ is the effective confining stress after $K_{0}$ consolidation; $t$ is the loading time; $\omega$ is the angular frequency; $\sigma_{s}$ is the static deviatoric stress; and $\sigma_{d}$ is the vertical dynamic stress. Tang et al. [21] and Yang et al. [22] indicated that the loading frequency in the subgrade was typically in a range of

\begin{tabular}{|c|c|c|c|c|c|c|c|}
\hline $\begin{array}{l}\rho \\
\left(\mathrm{g} / \mathrm{cm}^{3}\right)\end{array}$ & $\begin{array}{c}w \\
(\%)\end{array}$ & $\begin{array}{l}w_{\mathrm{p}} \\
(\%)\end{array}$ & $\begin{array}{l}w_{\mathrm{L}} \\
(\%)\end{array}$ & $\begin{array}{l}S_{\mathrm{r}} \\
(\%)\end{array}$ & $\begin{array}{c}\alpha \\
\left(\mathrm{MPa}^{-1}\right)\end{array}$ & $\begin{array}{c}c \\
(\mathrm{kPa})\end{array}$ & $\varphi\left({ }^{\circ}\right)$ \\
\hline 2.1 & 33.0 & 22.0 & 35.4 & 97.0 & 0.37 & 9.2 & 30.0 \\
\hline
\end{tabular}

TABLE 1: Physical and mechanical properties of the saturated silty clay.

0.5 to $3 \mathrm{~Hz}$, and $\mathrm{Lu}$ et al. [23] found that the lower one (e.g., less than $1 \mathrm{~Hz}$ ) played a dominant effect. Thus, $0.5 \mathrm{~Hz}$ was selected in this study. CSR was determined as $0.125,0.15$, 0.25 , and 0.3 , and SDR was adopted as $0,0.15,0.2$, and 0.25 .

Figure 1 shows the schematic of the loading process used in this study. The soil specimen was consolidated under $K_{0}$ condition $\left(K_{0}=0.606\right)$ to restore the initial stress state of the specimen. The effective confining stress was determined as $80 \mathrm{kPa}$ to simulate the actual confining pressure. A static deviatoric stress corresponding to the desired SDR was applied first under an undrained condition. Then a dynamic stress that corresponded to the desired CSR was applied until reaching the termination condition. The dynamic stress was not terminated until the soil specimen failed or the dynamic strain became stable. The failure state was defined as the specimen reaching a dynamic axial strain of $10 \%$ as the soil specimen had an appreciable lateral swelling deformation. Table 2 lists all the dynamic triaxial tests conducted in this study.

2.3. Determination of Dynamic Parameters. Regarded as a viscoelastic material, soil has two key parameters, resilient modulus $\left(M_{R}\right)$ and dynamic damping ratio $(D)$, which can be commonly determined based on the hysteresis curves from the dynamic triaxial test. Figure 2 shows the schematic for determining the two dynamic parameters of soil from the dynamic triaxial test. By drawing a line connecting the lowest point and the vertex of a hysteresis loop in the curve of vertical strain versus vertical dynamic stress, $M_{R}$ and $D$ can be obtained by the following expressions:

$$
\begin{gathered}
M_{R}=\frac{\sigma_{\mathrm{d} A}-\sigma_{\mathrm{d} C}}{\varepsilon_{\mathrm{d} A}-\varepsilon_{\mathrm{d} B}}, \\
D=\frac{S_{\text {shade }}}{2 \pi S_{\triangle A B C}},
\end{gathered}
$$

where $\sigma_{\mathrm{d} A}$ and $\sigma_{\mathrm{d} C}$ are the axial dynamic stresses at the vertex and low point of a hysteresis loop, respectively; $\varepsilon_{\mathrm{d} A}$ and $\varepsilon_{\mathrm{d} C}$ are the corresponding dynamic axial strains at $\sigma_{\mathrm{d} A}$ and $\sigma_{\mathrm{dC}}$, respectively; $S_{\text {shade }}$ is the area of hysteresis loop, which represents the loss of energy in a cycle; and $S_{\triangle A B C}$ is the area of triangle $A B C$, which represents the maximum elastic strain energy.

\section{Test Results and Discussion}

This section mainly introduces the soil behaviors of the soil under the modeled traffic cyclic loading, and the influences 


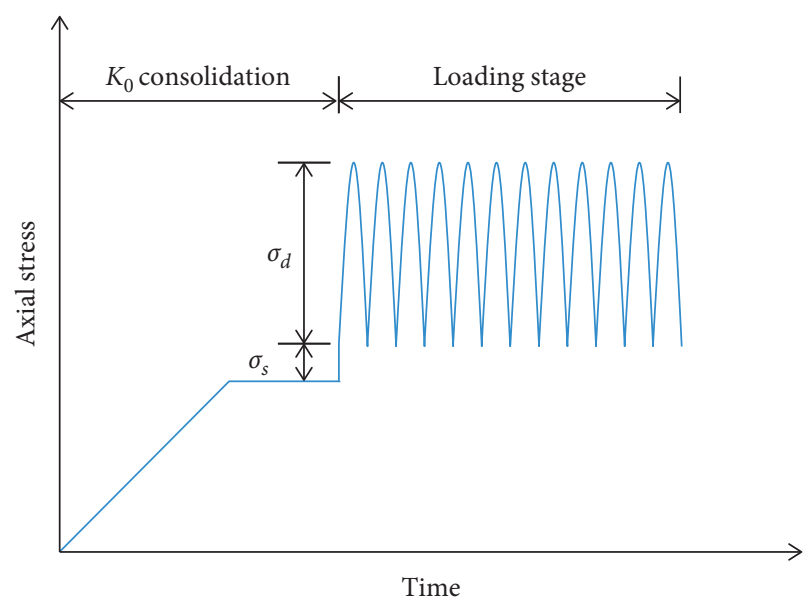

FIgURE 1: Schematic of the loading time-history curve.

Table 2: Dynamic triaxial test scheme.

\begin{tabular}{lccc}
\hline Test no. & OCR & CSR & SDR \\
\hline C-1 & 1.0 & 0.30 & 0 \\
C-2 & 1.0 & 0.25 & 0 \\
C-3 & 1.0 & 0.15 & 0 \\
C-4 & 1.0 & 0.125 & 0 \\
C-5 & 1.0 & 0.15 & 0.15 \\
C-6 & 1.0 & 0.15 & 0.20 \\
C-7 & 1.0 & 0.15 & 0.25 \\
C-8 & 0.5 & 0.25 & 0 \\
C-9 & 1.5 & 0.25 & 0 \\
C-10 & 2.0 & 0.25 & 0 \\
\hline
\end{tabular}

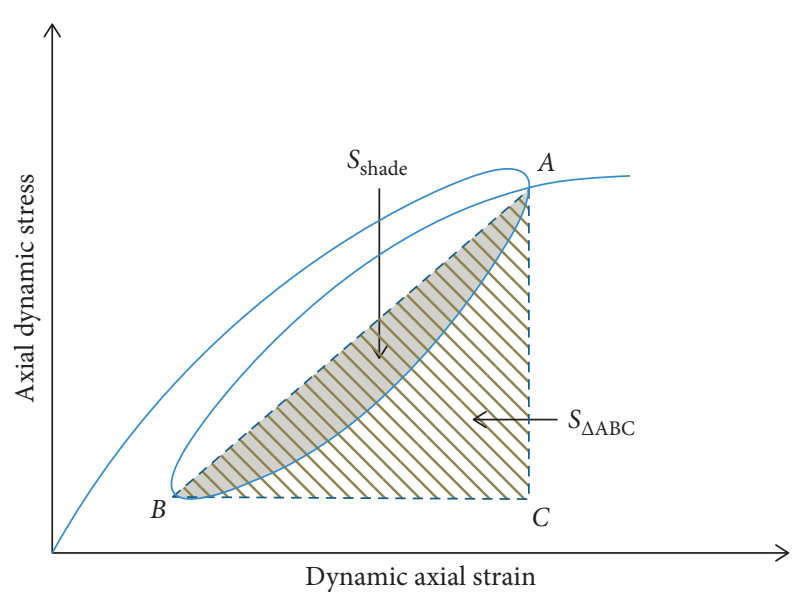

FIGURE 2: Determination of dynamic properties.

of CSR, SDR, and OCR on the dynamic parameters of the soil are discussed.

3.1. Effect of CSR. Figure 3 shows the results of the triaxial tests at different CSR. As expected, the dynamic axial strain of the soil specimen increased with an increase in CSR as shown in Figure 3(a). At CSR $=0.125$, the dynamic axial strain reached a constant about $0.87 \%$, which was far less than the termination standard of $10 \%$, while at $\operatorname{CSR}=0.3$, the dynamic axial strain of the soil specimen abruptly increased and exceeded $10 \%$ within limited cycles.

Figure 3(b) shows that the soil specimens had a maximum increment in excess pore pressure of $18.5 \mathrm{kPa}$ at $\mathrm{CSR}=0.125$ and approximately $36 \mathrm{kPa}$ at $\mathrm{CSR}=0.25$ and 0.30 . The higher increment in excess pore water pressure led to a larger reduction in effective stress. Consequently, the soil specimen easily failed under a high CSR. Based on the test results, CSR $=0.25$ was defined as the critical CSR of the tested saturated silty clay.

Figure 4 shows the relation between the dynamic parameters (i.e., $M_{R}$ and $D$ ) and the dynamic axial strain at different CSR. Similar to other studies $[24,25], M_{R}$ and $D$ were strongly dependent on CSR. $M_{R}$ and $D$ were almost kept constant when the saturated silty clay was subjected to a small CSR (i.e., CSR $=0.125$ ), as it basically behaved in an elastic state. At CSR $=0.25$ and $0.30, M_{R}$ decreased and $D$ increased with the increase of the dynamic axial strain, and they gradually approached the constant values. With the increase of CSR, the softening of $M_{R}$ and the increase of $D$ become significant. This phenomenon could be explained by the fact that the large dynamic stress caused the large accumulated dynamic axial strain of the soil specimen, leading to a significant energy consumption between soil skeletons. As a result, $D$ increased gradually with the increase of CSR.

3.2. Effect of $S D R$. Figure 5 shows the results of the triaxial tests at different SDR. SDR had a significant effect on the dynamic behavior of the saturated silty clay. The soil specimen failed at $\mathrm{CSR}=0.15$ and $\mathrm{SDR}=0.25$. Although the CSR of 0.15 was less than the critical CSR without considering SDR effect (i.e., 0.25), the increase in SDR accelerated the soil specimen failure. Figure 5(b) shows that the maximum increment in excess pore pressure increased with the increase of SDR and the soil specimen easily failed under a high CDR. As a result, the coupling effect on the soil dynamic behavior shall be considered to determine the critical CSR in design.

Figure 6 shows the relation between the dynamic parameters (i.e., $M_{R}$ and $D$ ) and the dynamic axial strain at different SDR. $M_{R}$ increased and $D$ decreased rapidly with a small increase in dynamic axial strain, followed by a gradually reduced rate. There is no question that $M_{R}$ and $D$ were strongly dependent on SDR. $M_{R}$ reduced and $D$ increased with the increase of SDR, while the effects became less significant after SDR was greater than 0.20. This phenomenon might be explained by a fact that the soil reached the critical limit state under a large SDR.

3.3. Effect of OCR. Figure 7(a) shows the variation of the dynamic axial strain with cyclic numbers at different OCR. When the soil specimen changed from a normally consolidated soil to a slightly overconsolidated soil $(\mathrm{OCR}=1.5)$, the dynamic axial strain had an obvious reduction but the reduction was not such appreciable when OCR increased from 1.5 to 2.0. Figure 7(b) shows a similar regulation that the maximum increment of excess 


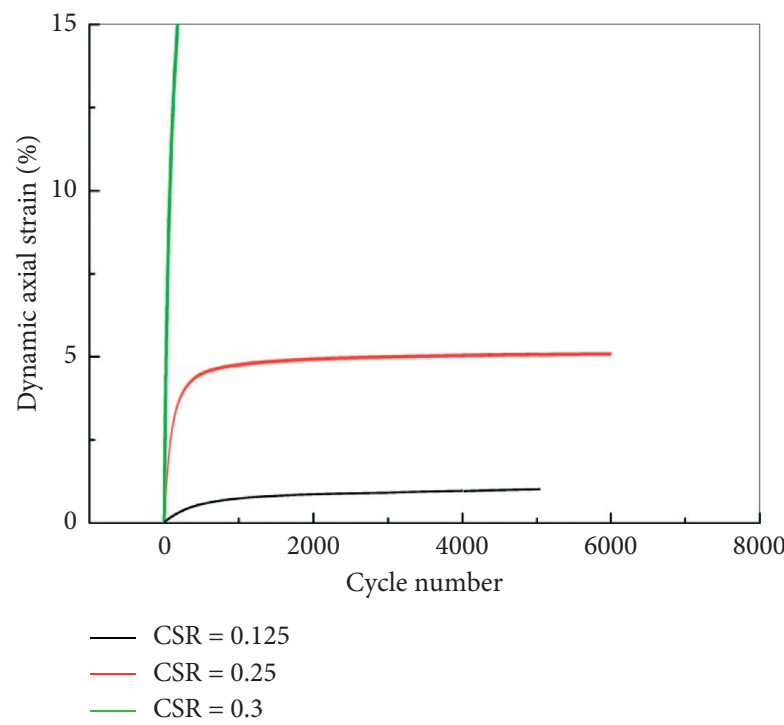

(a)

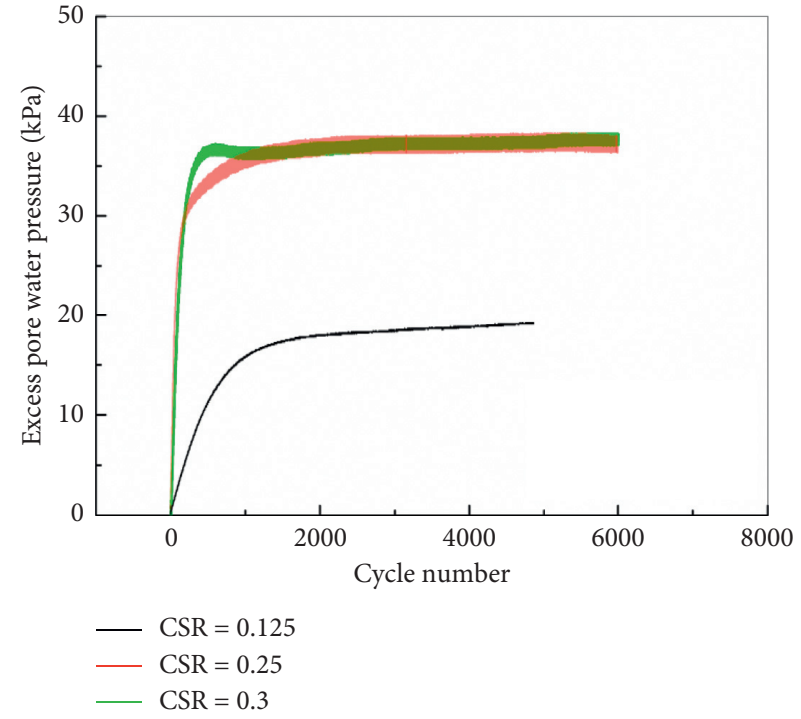

(b)

FIGURE 3: Dynamic response of soil specimen at different CSR: (a) dynamic axial strain; (b) excess pore water pressure.

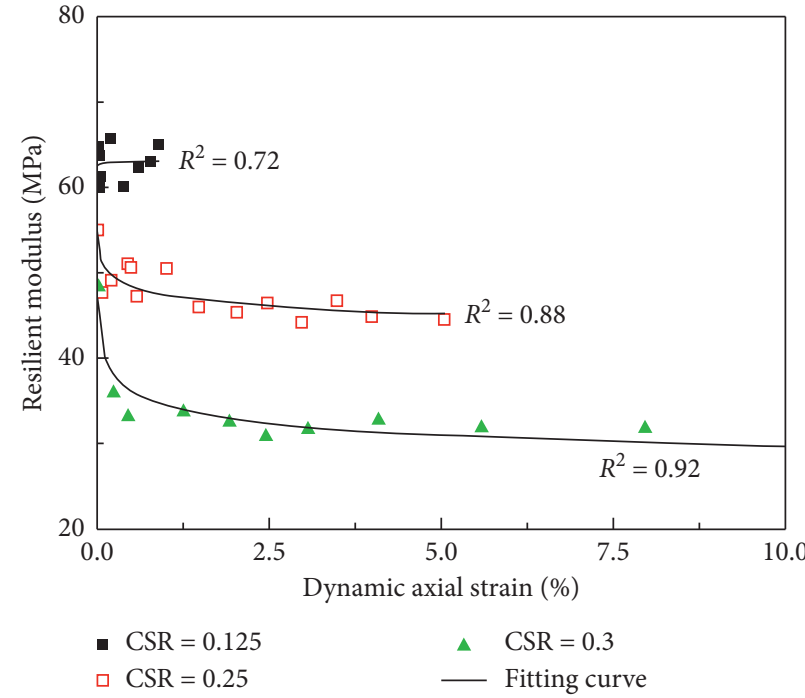

(a)

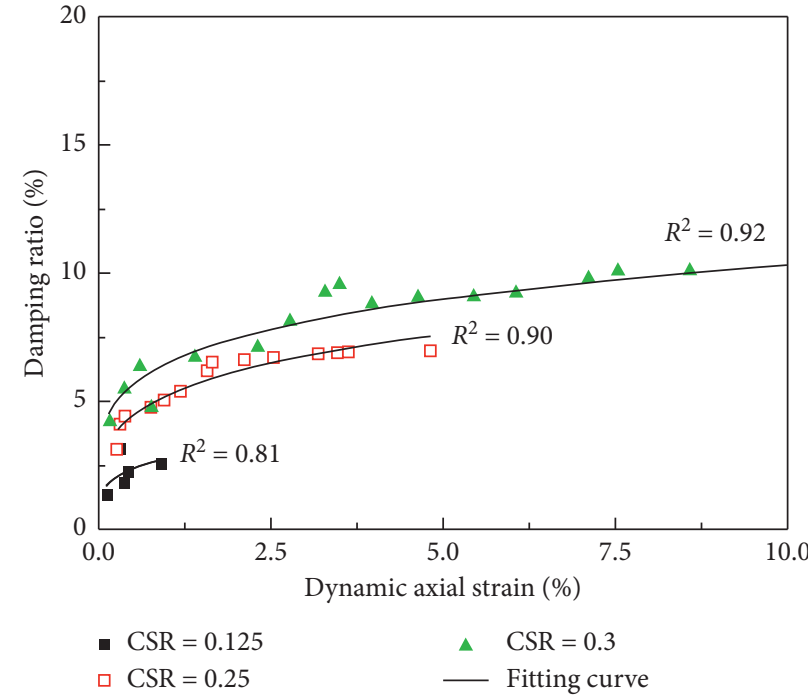

(b)

FIGURE 4: Variations of dynamic parameters with dynamic axial strain at different CSR: (a) $M_{R}$; (b) D.

pore water pressure was similar when OCR increased from 1.5 to 2.0 . It is interesting to note that the excess pore water pressure in test $\mathrm{C}-9(\mathrm{OCR}=1.5)$ fluctuated periodically, approximating 1000 cycles; however, the wave of the measured pore pressures was not observed in other tests. The wave of the measured pore pressures in test C-9 $(\mathrm{OCR}=1.5)$ could be due to the fluctuation of the axial dynamic stress.

Figure 8 shows the relation between the dynamic parameters (i.e., $M_{R}$ and $D$ ) and the dynamic axial strain at different OCR. The softening of $M_{R}$ and the increase of $D$ became significant when OCR changed from 1.5 to 1.0. From a practical point of view, proper compaction of subgrade has significant benefit on improving the soil dynamic behavior.

\section{Empirical Method for Determining Resilient Modulus}

The empirical models of damping ratio are usually a polynomial function depending on the ratio of resilient modulus at current strain to the initial dynamic elastic modulus [26-29]. A damping ratio model is not established in this study as it is difficult to accurately determine the initial dynamic elastic modulus in the dynamic triaxial test. Considering that resilient modulus as well as its 

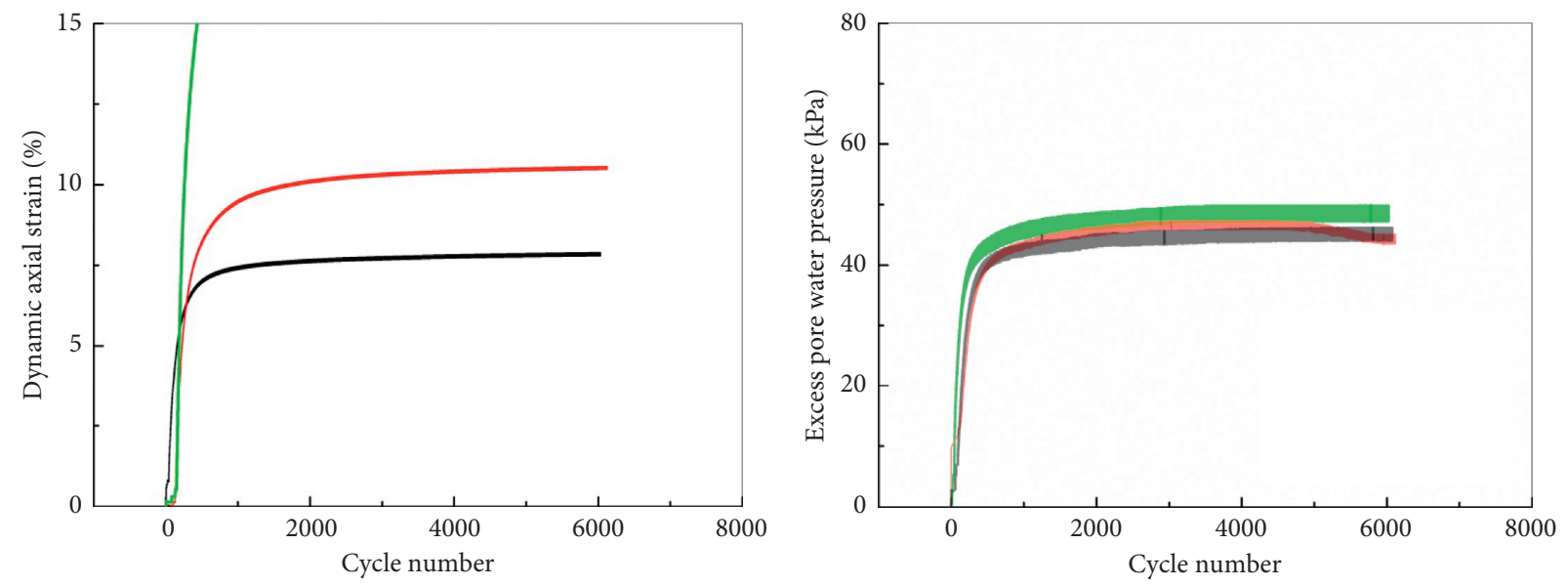

$$
\begin{aligned}
& \mathrm{CSR}=0.15 \\
& -\mathrm{SDR}=0.25 \\
& \text { SDR }=0.20 \\
& \mathrm{SDR}=0.15
\end{aligned}
$$

(a)

(b)

FIGURe 5: Dynamic response of soil specimen at different SDR: (a) dynamic axial strain; (b) excess pore water pressure.

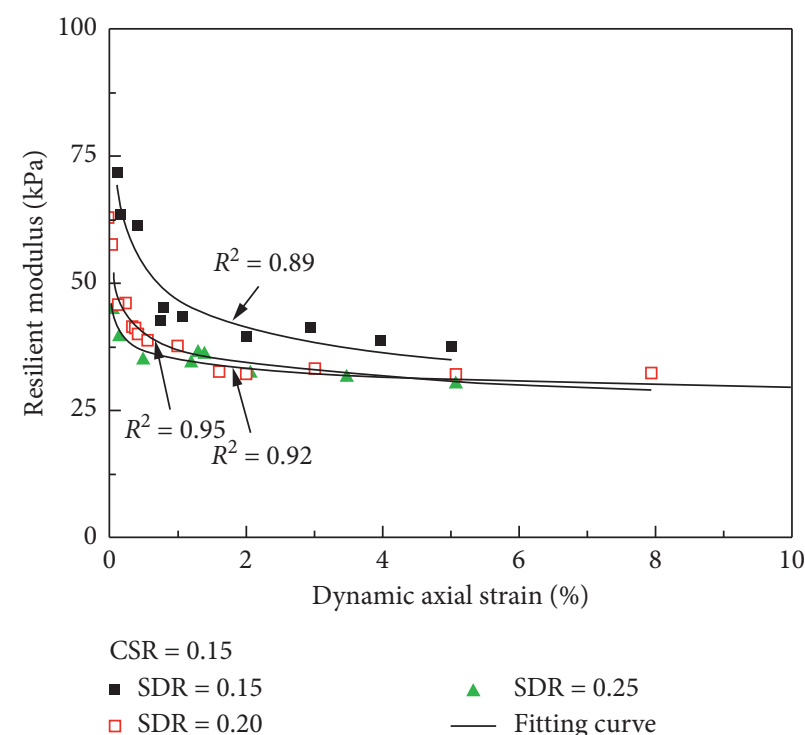

(a)

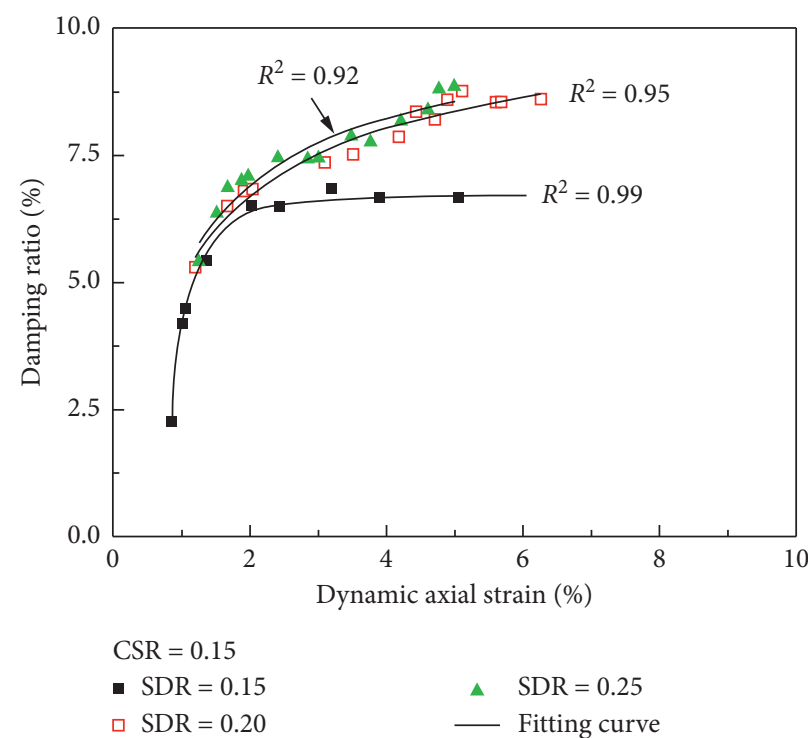

(b)

FIgURE 6: Variations of dynamic parameters with dynamic axial strain at different SDR: (a) $M_{R}$; (b) D.

deterioration is an important parameter for subgrade design, only an empirical method of resilient modulus model considering the influence factors of CSR, SDR, and OCR is established in this section.

4.1. Proposed Empirical Method. Based on the above analyses, the resilient modulus of the soil is dependent on CSR, SDR, and OCR. Hardin and Drnevich [29] proposed an empirical model to exhibit the nonlinear variation of $M_{R}$ with the increase of dynamic axial strain. However, in this model, the initial dynamic elastic modulus of the soil should be determined first. Generally, there are three methods to determine the initial dynamic elastic modulus: (a) in-door laboratory test, including resonant column test and dynamic triaxial test; (b) dynamic filed test, including shear wave velocity test; and (c) empirical equation, including the methods by Mojezi et al. [26] and Shan et al. [30]. The initial dynamic elastic modulus of soil is obtained under a small strain less than $10^{-4}$. The initial dynamic elastic modulus obtained by the resonant column test is more accurate than that by the dynamic triaxial test, as this dynamic 

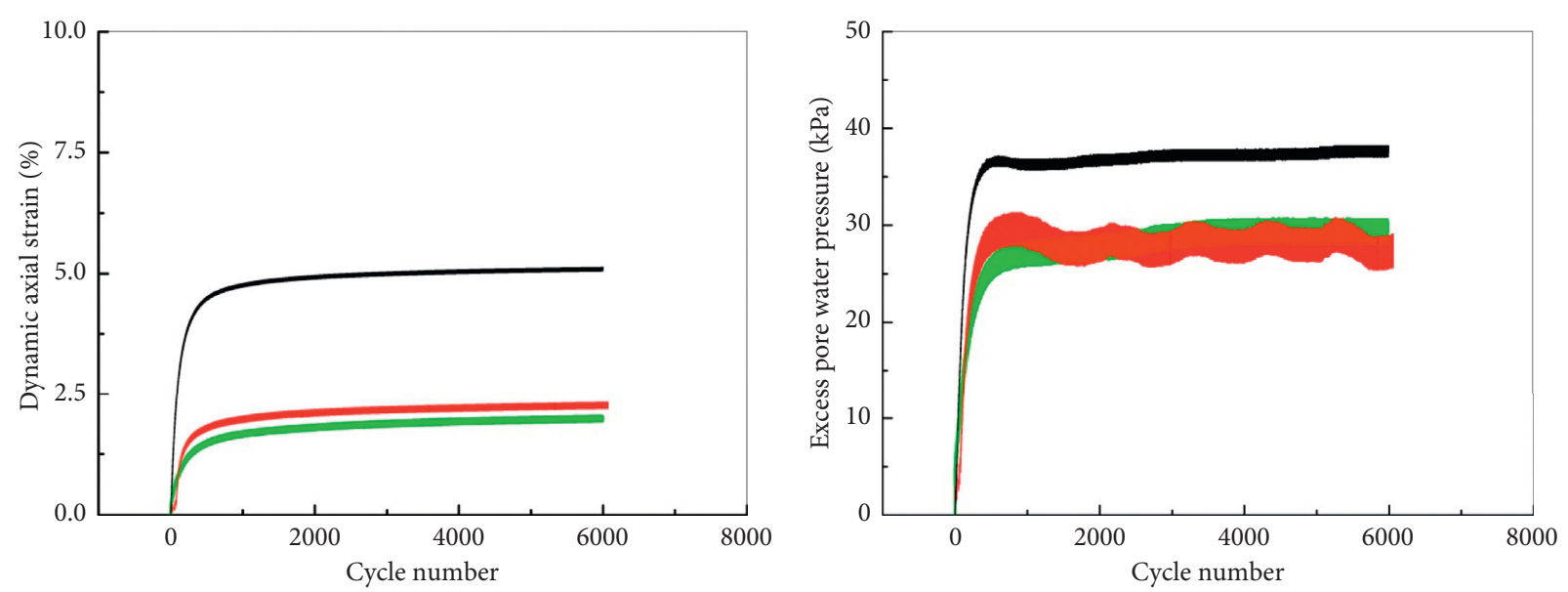

$$
\begin{aligned}
\text { CSR } & =0.25 \\
\text { OCR } & =1 \\
- \text { OCR } & =1.5 \\
\text { OCR } & =2
\end{aligned}
$$

$$
\begin{aligned}
\text { CSR } & =0.25 \\
\text { OCR } & =1 \\
\text { OCR } & =1.5 \\
\text { OCR } & =2
\end{aligned}
$$

(a)

(b)

FIGURE 7: Dynamic response of soil specimen at different OCR: (a) dynamic axial strain; (b) excess pore water pressure.

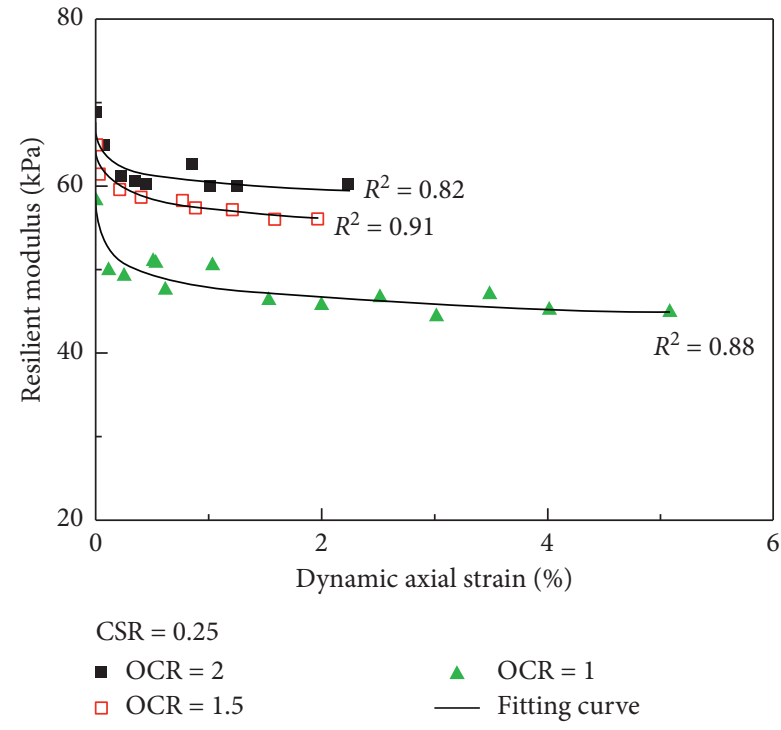

(a)

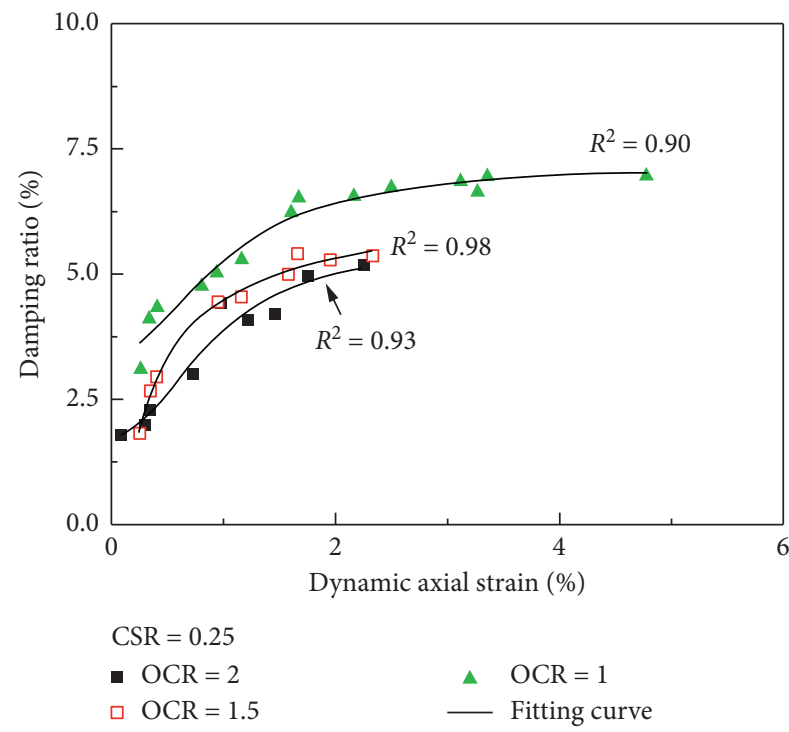

(b)

Figure 8: Variations of dynamic parameters with dynamic axial strain at different OCR: (a) $M_{R}$; (b) D.

test yields the shear strain level from $10^{-6}$ to $10^{-4}$. Taking this study for instance, the initial dynamic strain of the soil samples was in a range of $10^{-3}$ to $10^{-2}$ from the dynamic triaxial test, which was larger than the strain range for the initial elastic dynamic modulus by one to two orders of magnitude. Despite the fact that the in-door laboratory test is far from the real condition in the field, it is still important because the test condition can be better controlled in the laboratory. The empirical equation can be used to estimate initial dynamic elastic modulus in primary design, as the soil behavior of the soils under dynamic conditions has strong relations with the characteristics of regional soils.

Zhou and Gong [31] indicated that $M_{R}$ attenuated exponentially with the dynamic axial strain based on the stresscontrolled triaxial tests of Hangzhou normally consolidated clay with a form as

$$
M_{R}=\alpha \varepsilon_{d}^{\beta}
$$


where $\alpha$ and $\beta$ are the undetermined coefficients, which could be influenced by soil properties and loading characteristics. However, it is still not clear how the soil properties and loading characteristics affect $\alpha$ and $\beta$. In this study, this exponential model was improved by separating the influences of CSR, SDR, and OCR from the coefficients of $\alpha$ and $\beta$ and establishing the empirical functions of $\alpha$ and $\beta$ related to CSR, SDR, and OCR based on the test results. Thus, the improved model is more applicable in practice than the model proposed by Zhou and Gong [31]. to

After taking logarithm on both sides, equation (3) turns

$$
\lg \left(M_{R}\right)=\lg a+\beta \lg \left(\varepsilon_{d}\right) .
$$

Thus, it is revealed that the relation between $M_{R}$ and $\varepsilon_{d}$ can be fitted by linear equation in a logarithmic coordinate system, and $\lg \alpha$ and $\beta$ are the intercept and the slope of the linear equation. According to equation (4), $\alpha$ and $\beta$ can be back-calculated based on the triaxial test results. Furthermore, their relations with the influence factors, including CSR, SDR, and OCR, can be unveiled.

Figure 9 includes the obtained $\lg \left(M_{R}\right)$ with $\lg \left(\varepsilon_{d}\right)$ from the tests under different CSR. As expected, the data points distributed almost linearly. Based on the best fitting lines for each test, the intercept and the slope (i.e., $\lg \alpha$ and $\beta$ ) of each line can be determined. Figure 10 shows the back-calculated $\alpha$ and $\beta$ varying with CSR. It can be seen that $\alpha$ and $\beta$ vary almost linearly with CSR. Based on the above analysis, the functions of $\alpha$ and $\beta$ dependent on CSR can be established. Similarly, the functions of the parameters $\alpha$ and $\beta$ dependent on SDR and OCR can be established based on the test results, respectively. Figures 11 and 12 show the back-calculated $\alpha$ and $\beta$ varying with SDR and OCR. The functions dependent on SDR were fitted by linear equation and quadratic equation, while those dependent on OCR were modeled by exponential equation.

The above analyses unveil the relations of $\alpha$ and $\beta$ dependent on CSR, SDR, and OCR, respectively. $\alpha$ and $\beta$ varied almost linearly with CSR. The functions of $\alpha$ and $\beta$ dependent on SDR were best fitted by linear equation and quadratic equation, respectively, while the functions of $\alpha$ and $\beta$ dependent on OCR were best fitted by an exponential equation. Accordingly, the functions of $\alpha$ and $\beta$ considering the combined effects of CSR, SDR, and OCR can be assumed to have the following forms by adopting the method of separation of variables:

$$
\begin{aligned}
& \alpha=k_{1} \cdot \mathrm{OCR}^{k_{2}} \cdot\left(a_{1}+a_{2} \cdot \mathrm{CSR}\right) \cdot\left(b_{1}+b_{2} \cdot \mathrm{SDR}\right), \\
& \beta=k_{3} \cdot \mathrm{OCR}^{k_{4}} \cdot\left(a_{3}+a_{4} \cdot \mathrm{CSR}\right) \cdot\left(b_{3}+b_{4} \cdot \mathrm{SDR}+b_{5} \cdot \mathrm{SDR}^{2}\right),
\end{aligned}
$$

in which, $a_{i}, b_{i}$, and $k_{i}(i=1,2,3,4,5)$ are the undetermined coefficients, which can be determined based on the triaxial test.

When performing a dynamic triaxial test, in the first step, $a_{i}$ can be obtained by changing different CSR, while keeping $\mathrm{SDR}=0$. Then, $b_{i}$ can be determined by changing different

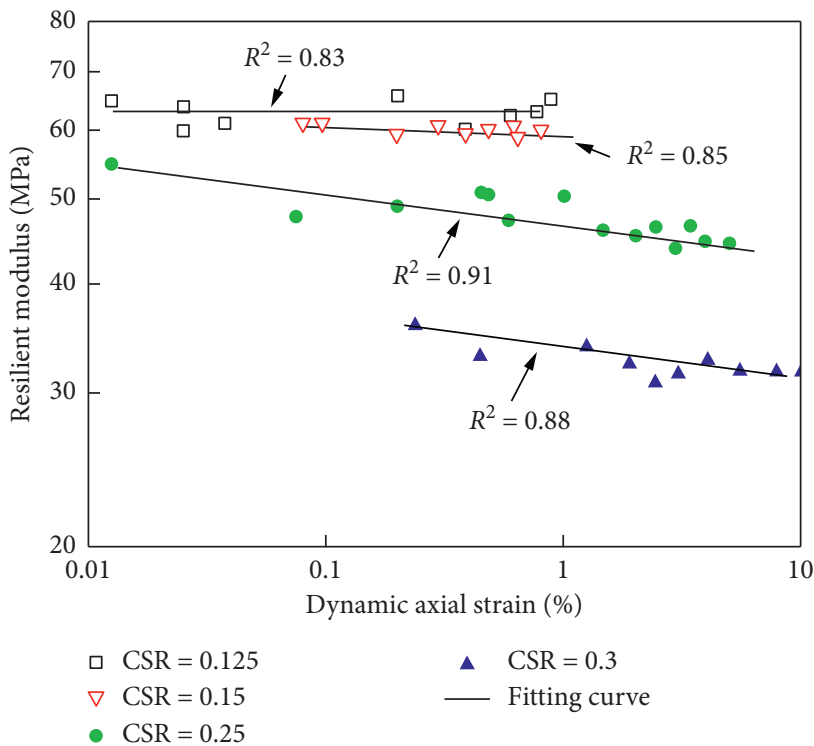

Figure 9: Variations of $\lg \left(M_{R}\right)$ with $\lg \left(\varepsilon_{d}\right)$ under different CSR.

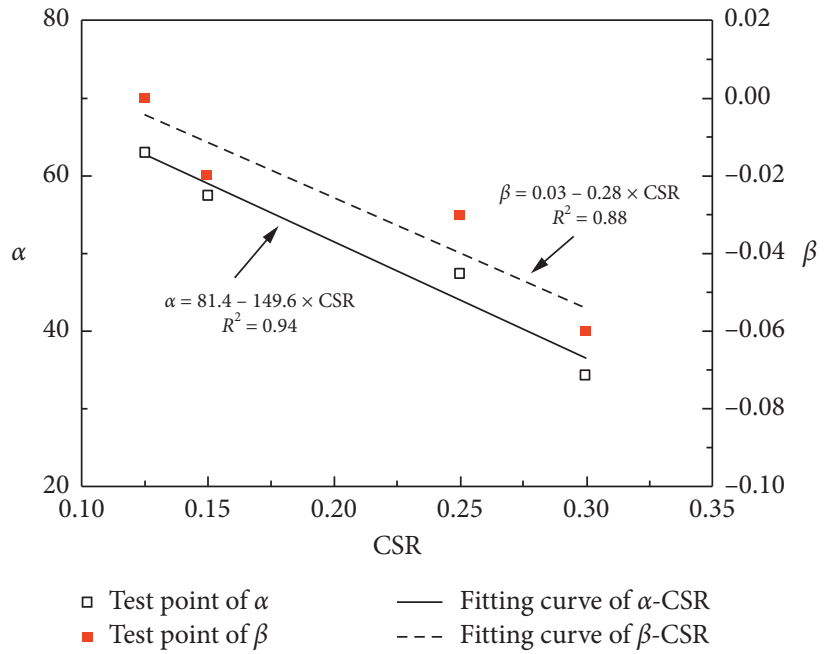

FIgURE 10: Variations of parameters $\alpha$ and $\beta$ with different CSR.

SDR, while keeping CSR constant. The third step is to obtain $k_{i}(i=2,4)$ by changing different OCR, while keeping CSR and SDR constant. Finally, $k_{i}(i=1,3)$ is used to balance equations (5a) and (5b).

Figure 13 shows a comparison of the calculated and measured values of $\alpha$ and $\beta$. The maximum deviation between the predicted $\alpha$ and $\beta$ from equations $5 \mathrm{a}$ and $5 \mathrm{~b}$ and between the back-calculated $\alpha$ and $\beta$ from the triaxial test results is less than $10 \%$, indicating that the developed functions can be used to well represent the combined effect of CSR, SDR, and OCR on the parameters $\alpha$ and $\beta$.

4.2. Verification. In this section, some test results from literatures were selected to further verify the proposed empirical method. Cai et al. [32] conducted a series of dynamic triaxial tests to study the influences of CSR and 


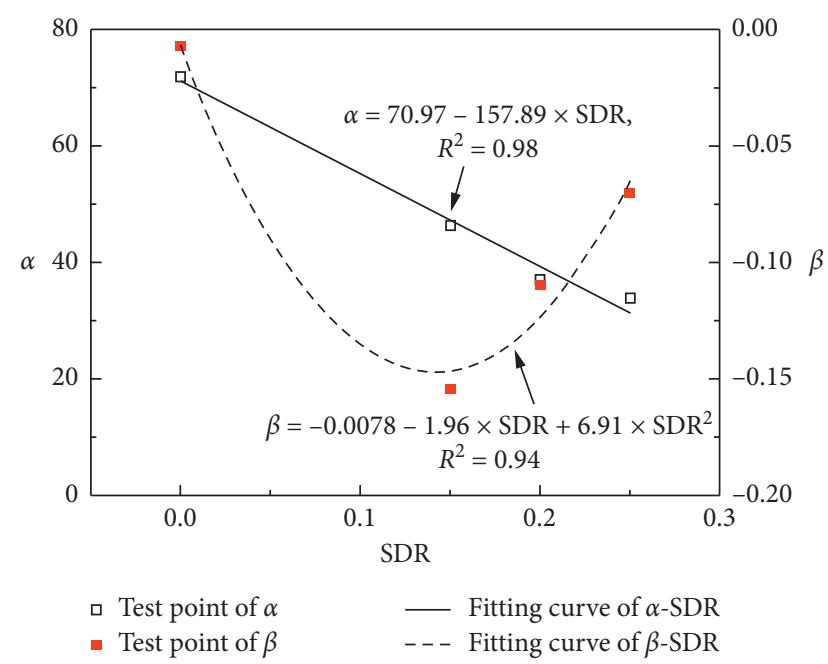

FIGURE 11: Variations of parameters $\alpha$ and $\beta$ with different SDR.

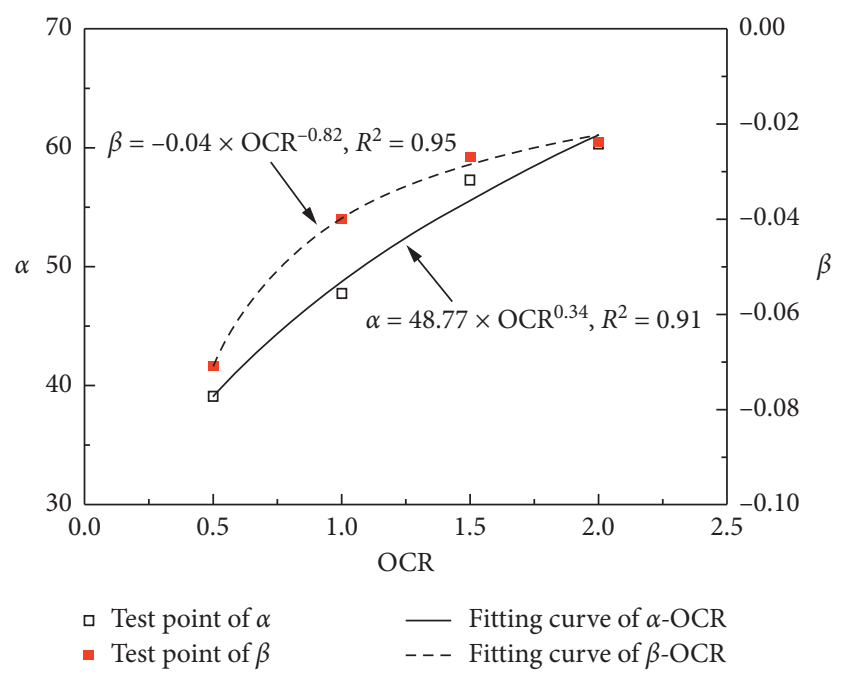

FIGURE 12: Variations of parameters $\alpha$ and $\beta$ with different OCR.

SDR on resilient modulus of the soft soil from Xiaoshan, China. Cyclic loading of sine wave with frequency of $1 \mathrm{~Hz}$ was applied to the soil samples. In the test, the CSR was selected as $0.583,0.749$, and 0.825 , and the SDR was taken as $0,0.1$, and 0.2 . The soil sample was prepared by the saturated remolded soft clay with liquid limit of $44.5 \%$ and plasticity index of 15.0. The soil sample was preconsolidated isotropically under a confining pressure of $100 \mathrm{kPa}$. Then, the required initial deviator stress was applied to the top of sample under undrained condition, followed by applying a vertical cyclic load. In the dynamic triaxial test conducted by Zhuang et al. [33], the cyclic loading was achieved with a sine wave. The SDR was taken as zero, the OCR of the soil sample was prepared to $1,2,3$, and 4 . The soil sample was prepared using saturated remolded soft clay from Nanjing, China, with liquid limit of $36.4 \%$ and plasticity index of 15.0. Xiong et al. [34] studied the dynamic characteristics of saturated soft silty clay from Ningbo, China. The cyclic loading with a sine wave type at a frequency of $1 \mathrm{~Hz}$ was applied. The soil sample was saturated remolded soft clay with liquid limit of $42 \%$ and plasticity index of 19.7. The soil sample was consolidated isotropically under confining pressure of 50 and $100 \mathrm{kPa}$, respectively. The applied vertical cyclic load was $10 \mathrm{kPa}$ and $20 \mathrm{kPa}$, respectively.

In the test by Cai et al. [32], as OCR was equal to 1 and only CSR and SDR were considered, equations $5 \mathrm{a}$ and $5 \mathrm{~b}$ can be simplified as

$$
\begin{aligned}
& \alpha=k_{1} \cdot\left(a_{1}+a_{2} \cdot \mathrm{CSR}\right) \cdot\left(b_{1}+b_{2} \cdot \mathrm{SDR}\right), \\
& \beta=k_{3} \cdot\left(a_{3}+a_{4} \cdot \mathrm{CSR}\right) \cdot\left(b_{3}+b_{4} \cdot \mathrm{SDR}+b_{5} \cdot \mathrm{SDR}^{2}\right) .
\end{aligned}
$$

In the test by Zhuang et al. [33], only OCR was considered; thus, equations $5 \mathrm{a}$ and $5 \mathrm{~b}$ can be simplified as

$$
\begin{aligned}
& \alpha=k_{1} \cdot \mathrm{OCR}^{k_{2}}, \\
& \beta=k_{3} \cdot \mathrm{OCR}^{k_{4}} .
\end{aligned}
$$

In the test by Xiong et al. [34], as only CSR was changed, equations $5 \mathrm{a}$ and $5 \mathrm{~b}$ can be simplified as

$$
\begin{aligned}
& \alpha=k_{1} \cdot\left(a_{1}+a_{2} \cdot \mathrm{CSR}\right), \\
& \beta=k_{3} \cdot\left(a_{3}+a_{4} \cdot \mathrm{CSR}\right) .
\end{aligned}
$$

Figure 14 shows the calculated $M_{R}$ by the proposed method versus the measured ones. The determined $\alpha$ and $\beta$ from equations $6 \mathrm{a}-(8 \mathrm{~b})$ are also included. In general, the calculated $M_{R}$ by the proposed method agreed well with the measured $M_{R}$ from the test results. The mean biases in the three cases were in a range of 1.0 to 1.13 with an average of 1.08. Small deviations between the calculated and measured $M_{R}$ still exist. As shown in Figures 4(a), 6(a), and 8(a), the measured $M_{R}$ fluctuated above and below the best fitting lines due to the complexity of the problem itself and the uncertainty associated with soil properties. The normal distributions of the residuals were checked as shown in Figure 15. The residuals approximate a normal distribution with an average of 0 , indicating that the proposed method yields good agreements with the reported measurements.

4.3. Comparison with Other Models. Hicks and Monismith [35] proposed an empirical model called $K-\theta$ model, which is one of the widely used models:

$$
M_{R}=K \theta^{\mathrm{n}},
$$

where $\theta$ is bulk stress and $K$ and $n$ are the regression parameters. In this study, the confining pressure $\sigma_{3}$ was kept constant at $80 \mathrm{kPa}$. $\theta$ can be rearranged by

$$
\theta=\frac{\sigma_{\mathrm{d}}+\sigma_{\mathrm{s}}+3 \sigma_{3}^{\prime}}{2 \sigma_{3}^{\prime}} 2 \sigma_{3}^{\prime}=2 \sigma_{3}^{\prime}(\mathrm{CSR}+\mathrm{SDR}+1.5) .
$$

Guo et al. 2013 [36] refined the $K-\theta$ model, further considering the effect of CSR: 


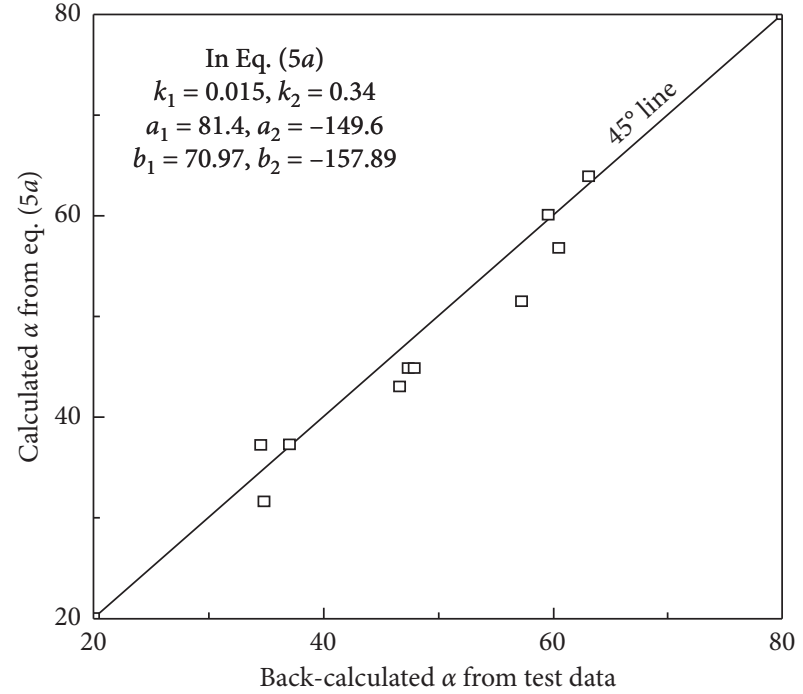

(a)

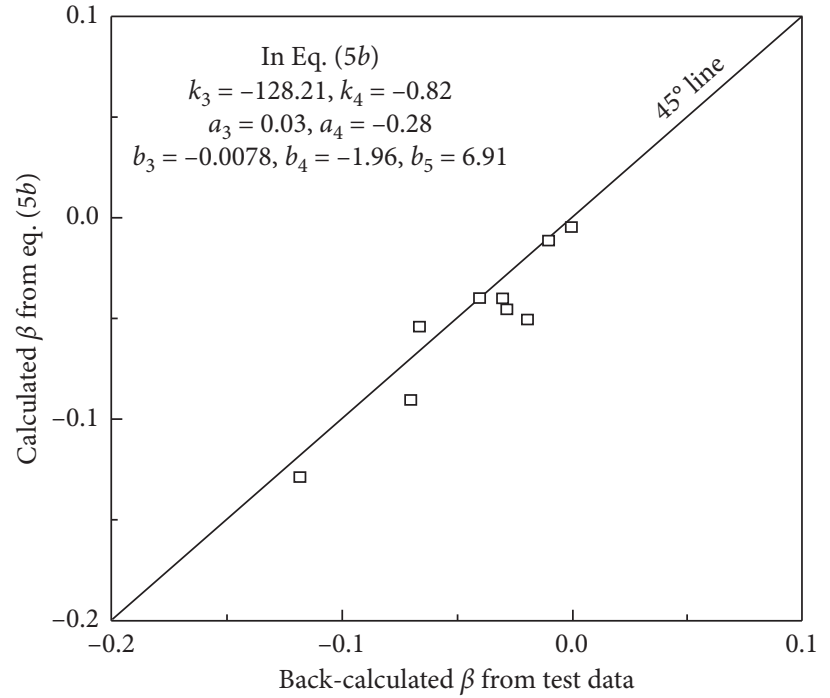

(b)

FIgURE 13: Comparison between predicted parameters $\alpha$ and $\beta$ and back-calculated results from test data.

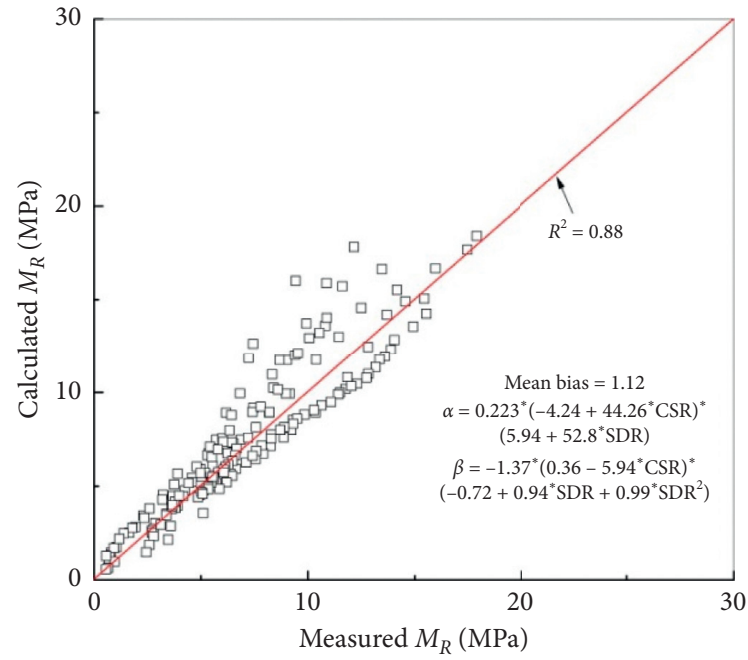

- $\quad$ Test data (Cai et al., 2007)

- $45^{\circ}$ line

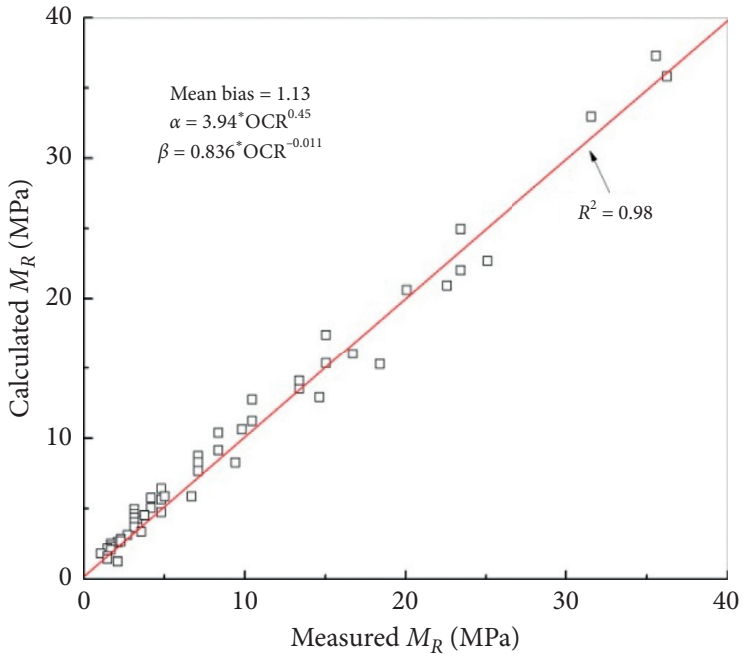

口 Test data (Zhuang et al., 2019)

- $45^{\circ}$ line

(a)

(b)

Figure 14: Continued. 


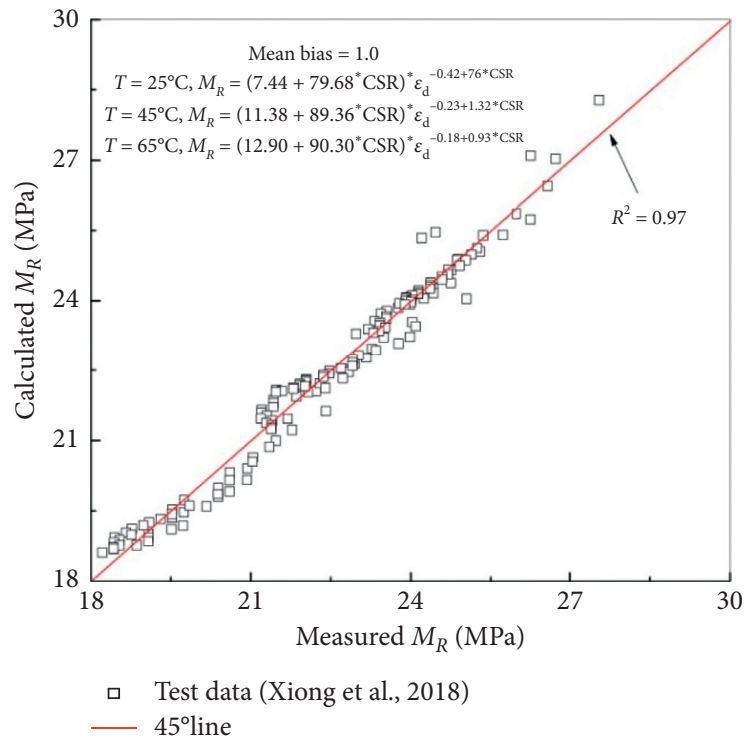

(c)

Figure 14: Comparison between calculated value and measured value of $M_{R}$.

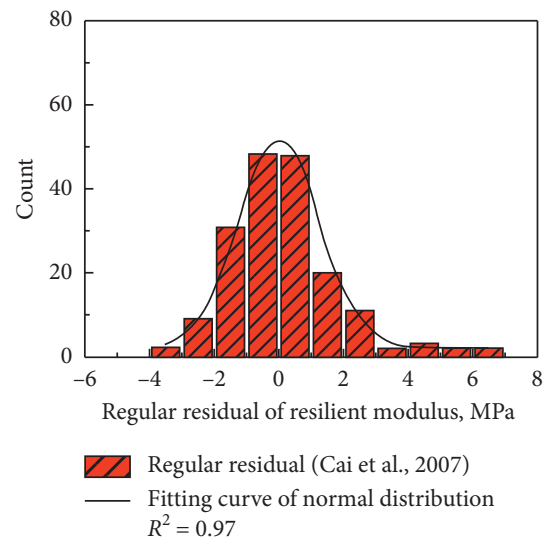

(a)

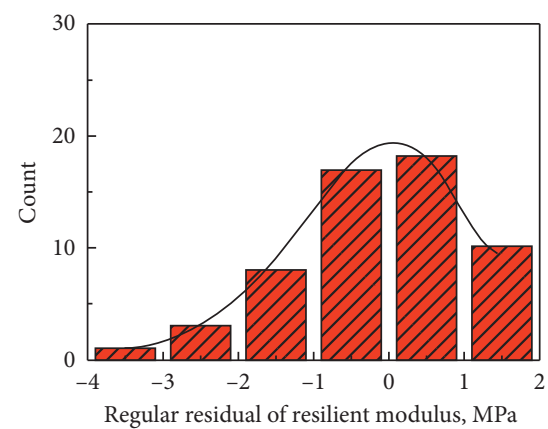

Z7 Regular residual (Zhuang et al., 2019) Fitting curve of normal distribution $R^{2}=0.98$

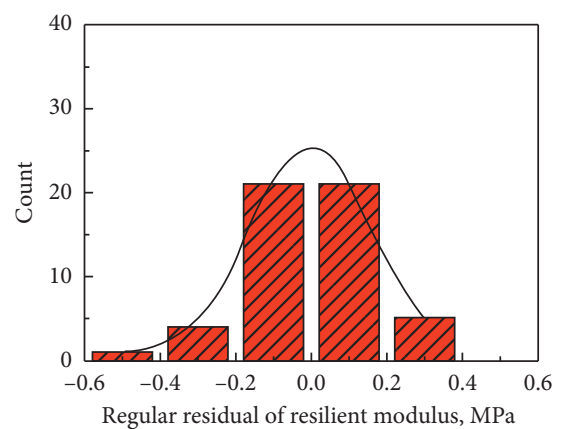

Regular residual (Xiong et al., 2018) Fitting curve of normal distribution $R^{2}=0.99$

(c)

Figure 15: Residual distribution of the predictions.

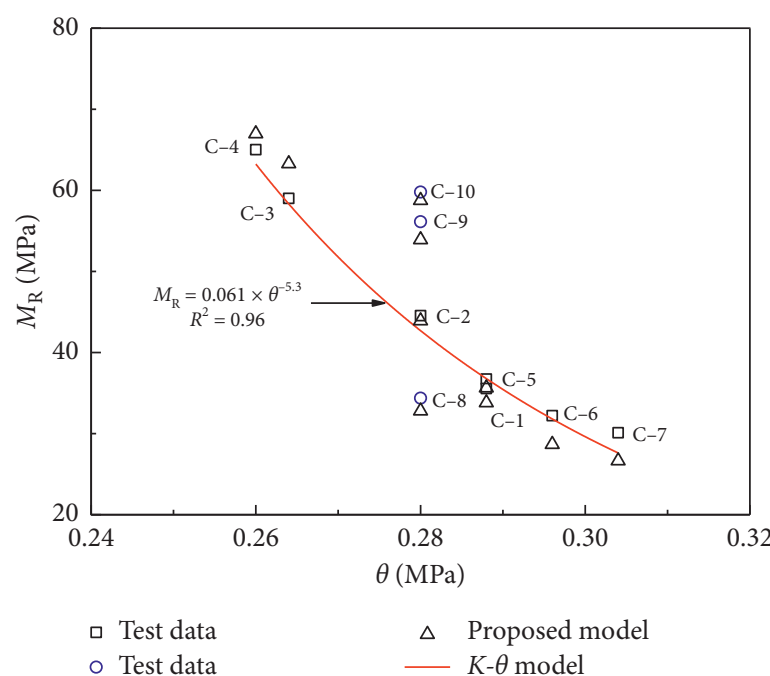

(a)

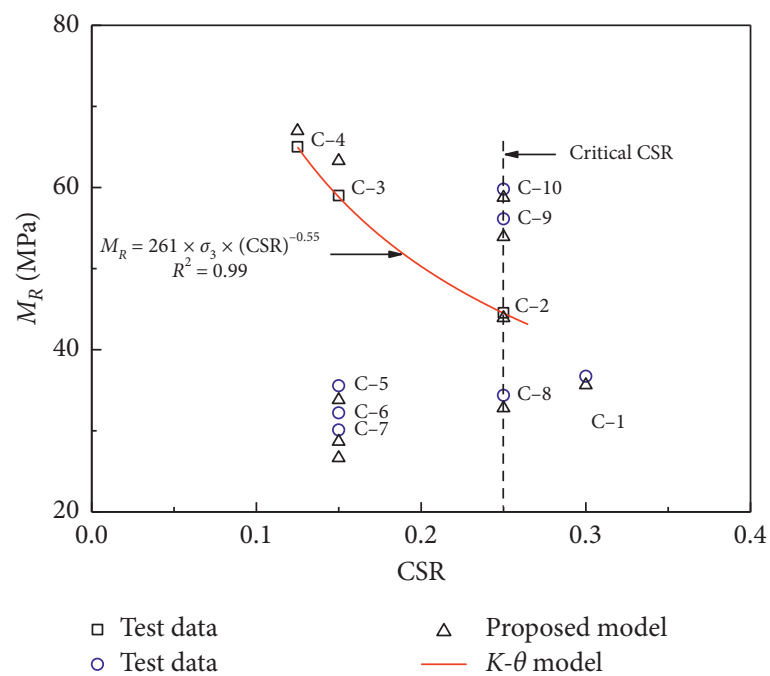

(b)

FIgure 16: Comparisons between different models: (a) $K-\theta$ model; (b) the Guo model. 


$$
M_{R}=k_{1} \sigma_{3}^{\prime}(C S R)^{k_{2}},
$$

where $k_{1}$ and $k_{2}$ are regression parameters. These two models can be used to predict the long-term resilient modulus, whereas the proposed model describes the softening of resilient modulus with dynamic strain. To make a comparison of the proposed model with these two models, the resilient modulus at a dynamic strain of 5\% was calculated, as the test results showed that the resilient modulus nearly approached a constant value after that strain.

Figure 16(a) shows the comparison of the proposed model and the $K-\theta$ model. The $K-\theta$ model obtained reasonable agreements with some test cases. However, as the $K-\theta$ model does not consider the effect of OCR, large deviations were noted for the tests Nos. C-8 to C-10. Figure 16(b) shows the comparison between the model proposed by Guo et al. [36] and the proposed model. The model proposed by Guo et al. [36] can reasonably reflect the effect of CSR, but large deviations were noticed if OCR and SDR changed. The proposed model yielded reasonable agreements with the test results, indicating that the primary advantage of the proposed model is that it can reasonably consider the combined effects of the influence factors of SCR, SDR, and OCR.

The analyses confirmed the applicability of the proposed model, but it should be realized that there are still some factors not considered in this method, for example, form of cyclic loading. The form of cyclic loading is dependent on some factors, including vehicle types and pavement types. It will be interesting if the proposed empirical method can be verified by the use of other cyclic forms in the future.

\section{Conclusions}

In this paper, a series of dynamic triaxial tests were conducted to investigate the dynamic behavior of the saturated silty clay under cyclic loading, and an empirical method was proposed to evaluate resilient modulus of the soil. Based on the test results and discussion, the following conclusions can be drawn:

(1) Under the cyclic loading, the dynamic axial strain of the soil increased faster when higher CSR and SDR and lower OCR were involved. The soil was prone to failure under a higher SDR, even though the applied CSR was less than the critical CSR. Proper compaction of subgrade has significant benefit on improving the soil dynamic behavior.

(2) The saturated silty clay performed a strain softening characteristic. The resilient modulus gradually reduced to a constant with the increase of cyclic numbers, and the dynamic damping ratio showed the opposite trend. The dynamic properties deteriorated significantly when higher CSR and SDR and lower OCR were involved.

(3) An empirical method was proposed considering the combined effects of CSR and SDR and OCR and verified through a comparison with the test results in this study and from literatures.

\section{Data Availability}

The data used to support the findings of this study are available from the corresponding author upon request.

\section{Conflicts of Interest}

The authors declare that they have no conflicts of interest.

\section{Acknowledgments}

The authors appreciate the financial support provided by the National Natural Science Foundation of China (NSFC) (Grants nos. 41772281 and 41972272) for this research.

\section{References}

[1] R. C. Gomes, J. A. Santos, and F. Lopez-Caballero, "Validation of a strategy to predict secant shear modulus and damping of soils with an elastoplastic model," KSCE Journal of Civil Engineering, vol. 20, no. 2, pp. 609-622, 2016.

[2] Y.-H. Miao, R.-Y. Sheng, J. Yin, F.-B. Zhou, and J.-F. Lu, "Dynamic characteristics of saturated soft clays under cyclic loading in drained condition," KSCE Journal of Civil Engineering, vol. 24, no. 2, pp. 443-450, 2020.

[3] Y. Cai, Y. Chen, Z. Cao, and C. Ren, "A combined method to predict the long-term settlements of roads on soft soil under cyclic traffic loadings," Acta Geotechnica, vol. 13, no. 5, pp. 1215-1226, 2018.

[4] Z. Lu, R. Fang, Y. Zhan, and H. Yao, "Study on the dynamic deformation of road high liquid limit subgrade soil," Advances in Civil Engineering, vol. 2019, pp. 1-7, 2019.

[5] Z. He, Y. Liu, H. Tang, Y. Xing, and H. Bian, "Experimental study on cumulative plastic deformation of coarse-grained soil high-grade roadbed under long-term vehicle Load," Advances in Civil Engineering, vol. 2018, pp. 1-8, 2018.

[6] J.-C. Chai and N. Miura, "Traffic-load-induced permanent deformation of road on soft subsoil," Journal of Geotechnical and Geoenvironmental Engineering, vol. 128, no. 11, pp. 907-916, 2002.

[7] Q.-L. Deng and X.-W. Ren, "An energy method for deformation behavior of soft clay under cyclic loads based on dynamic response analysis," Soil Dynamics and Earthquake Engineering, vol. 94, pp. 75-82, 2017.

[8] L. S. Tang, H. K. Chen, and Y. L. Sun, "Traffic-load-induced dynamic stress accumulation in subgrade and subsoil using small scale model tests," Geomechanics and Engineering, vol. 16, no. 2, pp. 113-124, 2018.

[9] C. Gu, Y. Wang, Y. Cai, and J. Wang, "Deformation characteristics of saturated clay in three-dimensional cyclic stress state," Canadian Geotechnical Journal, vol. 56, no. 12, pp. 1789-1802, 2019.

[10] L. Guo, J. Chen, J. Wang, Y. Cai, and P. Deng, "Influences of stress magnitude and loading frequency on cyclic behavior of K0-consolidated marine clay involving principal stress rotation," Soil Dynamics and Earthquake Engineering, vol. 84, pp. 94-107, 2016.

[11] Y. Zhao, X. Du, B. Xiong, and D. Zhang, "Experimental study on dynamic characteristics of marine soft clay in North 
China," Journal of Coastal Research, vol. 83, no. 1, pp. $474-478,2019$.

[12] S. Y. Thian and C. Y. Lee, "Cyclic stress-controlled tests on offshore clay," Journal of Rock Mechanics and Geotechnical Engineering, vol. 9, no. 2, pp. 376-381, 2017.

[13] Y. Shen, W. H. Du, and H. L. Liu, "Amplitude ratio effect on dynamic characteristics of remolded soft clay under train loads," Soil Mechanics and Foundation Engineering, vol. 55, no. 4, pp. 249-257, 2018.

[14] Y. Q. Cai, T. Y. Wu, and L. Guo, "Stiffness degradation and plastic strain accumulation of clay under cyclic load with principal stress rotation and deviatoric stress variation," Journal of Geotechnical and Geoenvironmental Engineering, vol. 144, no. 5, Article ID 4018021, 2018.

[15] F. Qiao, J. Bo, W. Qi et al., "Study on the dynamic characteristics of soft soil," RSC Advances, vol. 10, no. 8, pp. 4630-4639, 2020.

[16] R. X. Jing, F. Zhang, and D. C. Feng, "Dynamic shear modulus and damping ratio of compacted silty clay subjected to freeze-thaw cycles," Journal of Materials in Civil Engineering, vol. 31, no. 10, Article ID 4019244, 2019.

[17] ASTM D4220/D4220M-14, Standard Practices for Preserving and Transporting Soil Samples, ASTM International, West Conshohocken, PA, USA, 2014.

[18] A. Karlstrom and A. Bostrom, "An analytical model for traininduced ground vibrations from railways," Journal of Sound and Vibration, vol. 292, no. 1-2, pp. 221-241, 2006.

[19] Z. P. Hu, R. Wang, and X. Ren, "Permanent deformation behavior of compacted loess under long-term traffic loading," Journal of Materials in Civil Engineering, vol. 31, no. 8, Article ID 4019157, 2019.

[20] J.-F. Lu and D.-S. Jeng, "A half-space saturated poro-elastic medium subjected to a moving point load," International Journal of Solids and Structures, vol. 44, no. 2, pp. 573-586, 2007.

[21] Y. Q. Tang, J. Zhou, and S. Liu, "Dynamic response and pore pressure model of the saturated soft clay around the tunnel under vibration loading of Shanghai subway," Engineering Geology, vol. 98, no. 3-4, pp. 126-132, 2008.

[22] Q. Yang, Y. Tang, B. Yuan, and J. Zhou, "Cyclic stress-strain behaviour of soft clay under traffic loading through hollow cylinder apparatus: effect of loading frequency," Road Materials and Pavement Design, vol. 20, no. 5, pp. 1026-1058, 2019.

[23] Z. Lu, R. Fang, and H. Yao, "Evaluation and analysis of the traffic load-induced settlement of roads on soft subsoils with low embankments," International Journal of Geomechanics, vol. 18, no. 6, Article ID 4018043, 2018.

[24] C. Gu, Y. Wang, and Y. Cui, "One-way cyclic behavior of saturated clay in 3D stress state," Journal of Geotechnical and Geoenvironmental Engineering, vol. 145, no. 10, Article ID 4019077, 2019.

[25] B. Lin, F. Zhang, and D. Feng, "Long-term resilient behaviour of thawed saturated silty clay under repeated cyclic loading: experimental evidence and evolution model," Road Materials and Pavement Design, vol. 20, no. 3, pp. 608-622, 2019.

[26] M. Mojezi, M. Biglari, M. K. Jafari, and I. Ashayeri, "Determination of shear modulus and damping ratio of normally consolidated unsaturated kaolin," International Journal of Geotechnical Engineering, vol. 14, no. 3, pp. 264-285, 2020.

[27] J. Zhang, R. D. Andrus, and C. H. Juang, "Normalized shear modulus and material damping ratio relationships," Journal of Geotechnical and Geoenvironmental Engineering, vol. 131, no. 4, pp. 453-464, 2005.
[28] L. R. Hoyos, A. J. Puppala, and P. Chainuwat, "Dynamic properties of chemically stabilized sulfate rich clay," Journal of Geotechnical and Geoenvironmental Engineering, vol. 130, no. 2, pp. 153-162, 2004.

[29] B. O. Hardin and V. P. Drnevich, "Shear modulus and damping: equations and curves," Journal of Terramechanics, vol. 98, no. SM7, pp. 667-692, 1972.

[30] Y. Shan, H.-H. Mo, S.-M. Yu, and J.-S. Chen, "Analysis of the maximum dynamic shear modulus and particle arrangement properties of saturated soft clay soils," Soil Mechanics and Foundation Engineering, vol. 53, no. 4, pp. 226-232, 2016.

[31] J. Zhou and X. Gong, "Strain degradation of saturated clay under cyclic loading," Canadian Geotechnical Journal, vol. 38, no. 1, pp. 208-212, 2001.

[32] Y. Q. Cai, J. Wang, and C. J. Xu, "Experimental study on dynamic elastic modulus and damping ratio of Xiaoshan saturated soft clay considering initial deviator stress," Chinese Journal of Rock and Soil Mechanics, vol. 28, no. 11, pp. 2291-2296, 2007.

[33] Y. Zhuang, W. Zhu, and F. Zhang, "Analysis of factors affecting dynamic modulus of elasticity of saturated silty clay and research on backbone curve model," Chinese Journal of Central South University (Science and Technology), vol. 50, no. 2, pp. 445-451, 2019.

[34] Y.-L. Xiong, G.-B. Liu, R.-Y. Zheng, and X.-H. Bao, "Study on dynamic undrained mechanical behavior of saturated soft clay considering temperature effect," Soil Dynamics and Earthquake Engineering, vol. 115, pp. 673-684, 2018.

[35] R. G. Hicks and C. L. Monismith, "Factors influencing the resilient properties of granular materials," Transportation Research Record, vol. 34, pp. 15-31, 1971.

[36] L. Guo, J. Wang, Y. Cai, H. Liu, Y. Gao, and H. Sun, "Undrained deformation behavior of saturated soft clay under long-term cyclic loading," Soil Dynamics and Earthquake Engineering, vol. 50, pp. 28-37, 2013. 